\title{
Analysis of Hereditary Nonpolyposis Colorectal Cancer in Malay Cohorts using Immunohistochemical Screening
}

\author{
Wan Khairunnisa Wan Juhari ${ }^{1}$, Wan Faiziah Wan Abdul Rahman ${ }^{2 *}$, Ahmad \\ Shanwani Mohd Sidek ${ }^{5}$, Muhammad Radzi Abu Hassan ${ }^{6}$, Khairul Bariah Ahmad \\ Amin Noordin ${ }^{4}$, Andee Dzulkarnaen Zakaria ${ }^{3}$, Finlay Macrae ${ }^{7}$, Bin Alwi Zilfalil ${ }^{1}$
}

\begin{abstract}
Background: Lynch syndrome (LS) is an inherited predisposition to colorectal, endometrial (uterine) and other cancers. Although most cancers are not inherited, about 5 percent $(\%)$ of people who have colorectal or endometrial cancer have the Lynch syndrome. It involves the alteration of mismatch repair (MMR) genes; MLH1, MSH2, MSH6 or PMS2. In this study, we analyzed the expression of MMR proteins in colorectal cancer in a Malay cohort by immunohistochemistry. Materials and Methods: A total of 17 patients were selected fulfilling one of the Bethesda criteria: colorectal cancer diagnosed in a patient aged less than 50 years old, having synchronous and metachronous colorectal cancer or with a strong family history. Immunohistochemical staining was performed on paraffin embedded tumour tissue samples using four antibodies: MLH1, MSH2, MSH6 and PMS2. Results: Twelve out of 17 patients $(\mathbf{7 0 . 6 \%})$ were noted to have a family history. A total of $41 \%(n=7)$ of the patients had abnormal immunohistochemical staining with one or more of the four antibodies. Loss of expression were noted in 13 tumour tissues with a negative staining score $<4$. Of 13 tumour tissues, four showed loss expression of MLH1. For PMS2, loss of expression were noted in five cases. Both MSH2 and MSH6 showed loss of expression in two tumour tissues respectively. Conclusions: Revised Bethesda criteria and immunohistochemical analysis constituted a convenient approach and is recommended to be a first-line screening for Lynch syndrome in Malay cohorts.
\end{abstract}

Keywords: Colorectal carcinoma - HNPCC - Lynch syndrome - immunohistochemistry - MMR

Asian Pac J Cancer Prev, 16 (9), 3767-3771

\section{Introduction}

Cancers of the colon and rectum accounted for almost 1 million new cases in 2002, 9.4\% of the world total reports (Parkin et al., 2005). Lynch syndrome (LS) is the most common hereditary cancer and account for $5-10 \%$ of total colorectal cancer (Cai et al., 2001). It is caused by mutations in mismatch repair (MMR) genes, MLH1, MSH2, MSH6 and PMS2 (Lynch et al., 2003). Being an autosomal dominant genetic variation, LS can be differentiated from sporadic colorectal cancer by the assessment of family history and based on young age at onset of malignancy (Haghighi et al., 2009). Individuals with LS are also predisposed to the development of cancer in extracolonic organs such as endometrial, stomach, ovary, small bowel, hepatobiliary tract, renal pelvis, ureter, skin, and brain (Lynch et al., 1999; Lynch et al., 2003). HNPCC can be differentiated from the sporadic colorectal cancer based on young age at onset of malignancy (Haghighi et al., 2009). Mutations in MLH1 and MSH2 genes account for almost $90 \%$ of the identified cases (Jasperson et al., 2010; Gala \& Chung, 2011), while $7 \%$ of mutations occurred in MSH6 gene, and 3\% for the remaining genes (Peltomaki et al., 2004). Single base pair mismatches and single nucleotide insertion/deletion loops are recognized by hMutSa (a heterodimer complex formed by the MSH1 and PMS2 proteins), whereas hMutS $\beta$ (a heterodimer complex formed by the MSH2 and MSH6 proteins) recognizes larger insertion deletion loops of two to eight nucleotides (Barrow et al., 2009). Malfunction in the coordination of the MMR genes results in the inability to repair error during DNA replication.

The gold standard for diagnostic of LS is germline mutation in MMR genes (Gala and Chung, 2011). Direct DNA sequencing (Sanger sequencing) is believed to be the key procedure for detecting mutations in the MMR genes. However, immunohistochemistry (IHC) is used to show abnormal MMR proteins expression in tumours

${ }^{I}$ Department of Paediatric, ${ }^{2}$ Department of Pathology, ${ }^{3}$ Department of Surgery, School of Medical Sciences, ${ }^{4}$ School of Dental Sciences, Universiti Sains Malaysia, Health Campus, Kelantan, ${ }^{5}$ Surgery Department, Hospital Raja Perempuan Zainab 2, Kota Bharu, ${ }^{6}$ Clinical Research Centre, Hospital Sultanah Bahiyah, Kedah, Malaysia, ${ }^{7}$ Department of Colorectal Medicine and Genetics, Royal Melbourne Hospital, Melbourne, Australia*For correspondence: wfaiziah@usm.my 
as an abnormal seen for LS guiding the selection of the appropriate gene for sequencing. The use of four MMR antibodies (MLH1, MSH2, MSH6 and PMS2) are recommended over the use of only two MMR antibodies (Arends et al., 2008). The sensitivity and specifity for MLH1 is $100 \%$ and $91.5 \%$ respectively. For the MSH2 gene mutation carrier, the sensitivity and specificity is $87.5 \%$ and $88.5 \%$ respectively (Barrow et al., 2010). This is the first LS study focusing on the Malay individuals. There are several reports on germline mutations and IHC analysis in Malaysian Lynch Syndrome patients in two LS genes (Murad et al., 2012; Zahary et al., 2012).

However, there were no reports on the Malay Lynch Syndrome patients. Therefore, this study aims to demonstrate the immunohistochemical staining analysis patterns from tumours in a group of Malay Lynch syndrome patients.

\section{Materials and Methods}

\section{Patient assessment}

Informed consent was obtained from the patients after the approval from the Universiti Sains Malaysia (USM) Research Ethics Committee and Medical Research and Ethics Committee (MREC), Ministry of Health Malaysia. Patients were recruited from three hospitals, Hospital Universiti Sains Malaysia, Kelantan, Hospital Sultanah Bahiyah, Kedah and Hospital Raja Perempuan Zainab 2, Kelantan. The samples recruitment was only be the Malay patients due to the demographic pattern with a high prevalence of Malay subjects in this three selected hospitals.

The patients were selected fulfilling one of the Bethesda criteria (Vasen et al., 2007) in which colorectal cancer diagnosed in a patient with the age of less than 50 years old, having synchronous and metachronous colorectal cancer or with a strong family history (Table 1). Informed consent was obtained from the patients.
The family history was assessed by personal interview and the detailed cancer diagnosis of the patients and their respective relatives were then validated against the hospital registry records and pathology reports.

\section{Sample collection and immunohistochemical staining}

For each patient's sample, a formalin-fixed paraffin embedded (FFPE) tissue block from biopsy or resected bowel specimen with $4 \mu \mathrm{m}$ thick was sectioned and mounted on to glass slide. The sections were then be dewaxed in xylene and rehydrated in graded alcohol concentrations to distilled water. The slides were then placed in Tris-EDTA buffer ( $\mathrm{pH} 9.0$ ) in a pressure cooker for antigen retrieval for 3 minutes $\left(121^{\circ} \mathrm{C}, 15 \mathrm{lb}\right)$. Slides were subsequently incubated at $40 \mathrm{C}$ overnight with $200 \mu 1$ of primary antibodies to MutL Protein Homolog 1 (MLH1), MutS Protein Homolog 2 (MSH2), MutS Protein Homolog 6 (MSH6) and Postmeiotic Segregation Increased 2 (PMS2). The detail of the antibodies are as in the Table 2.

Endogenous peroxidase activity was blocked by incubation with peroxidase blocking reagent for 5 minutes. The slides were then washed thoroughly with Tris-buffered saline (TBS) to remove excess reagents after overnight incubation. Two drops of Horseradishperoxidase (HRP) labelled polymer conjugated to secondary antibody were applied to the slides and were incubated for 45 minutes. Subsequent washing by TBS buffer was performed followed by incubating $200 \mu 1$ of DAB substrate chromogen for 3 minutes. The slides were counterstained with hematoxylin, dehydrated and mounted.

Normal appendix tissue was used as the external positive control while the lymphocytes and benign colonocytes served as an internal positive control. Loss of expression was recorded when nuclear staining is observed in normal appendix tissue but not in adjacent malignant cells.

Table 1. Features of HNPCC-related CRC Patient with their Respective Age of Onset and Family History

\begin{tabular}{|c|c|c|}
\hline Patient ID & Age of onset & Family history \\
\hline$\overline{\mathrm{F} 1}$ & 26 & $\begin{array}{l}\text { Two second degree relatives had ovarian cancer, one second degree relative had breast cancer and } \\
\text { one first degree relative (mother) had ovarian cancer at the age of } 40 \text { years old }\end{array}$ \\
\hline $\mathrm{F} 2$ & 50 & No family history \\
\hline F3 & 39 & One second degree relative had breast cancer at the age of $>50$ years old \\
\hline $\mathrm{F} 4$ & 27 & $\begin{array}{l}\text { One first degree relative (mother) had colorectal cancer at the } 53 \text { years old, two second degree } \\
\text { relatives had colorectal cancer at }>50 \text { years old }\end{array}$ \\
\hline F5 & 43 & One first degree relative (sister) had colorectal cancer at the age of 58 years old \\
\hline F7 & 53 & $\begin{array}{l}\text { One first degree relative (daughter) had colorectal cancer at the age of } 27 \text { years old, two first degree } \\
\text { relatives had colorectal cancer at the age of }>50 \text { years old }\end{array}$ \\
\hline F8 & 58 & One first degree relative (sister) had colorectal cancer at the age of 43 years old \\
\hline F10 & 29 & One first degree relative (mother) had colorectal cancer at the age of 53 years old \\
\hline F11 & 23 & No family history \\
\hline F12 & 53 & One first degree relative (daughter) had colorectal cancer at the age of 29 years old \\
\hline F13 & 37 & Second degree relative had endometrial cancer at the age of $>50$ years old \\
\hline F14 & 54 & $\begin{array}{l}\text { One first degree relative (brother) had colorectal cancer at the age of } 39 \text { years old, one first degree } \\
\text { relative (sister) had uterus cancer at the age of } 51 \text { years old and one first degree relative (mother) } \\
\text { had brain cancer at the age of } 60 \text { years old }\end{array}$ \\
\hline F16 & 44 & Unknown family history \\
\hline F18 & 25 & Unknown family history \\
\hline F19 & 48 & Unknown family history \\
\hline $\mathrm{F} 20$ & 29 & Two second degree relatives had colorectal cancer at $<50$ years old \\
\hline $\mathrm{F} 21$ & 26 & One first degree relative (mother) had ovarian cancer at the age of 59 years old \\
\hline
\end{tabular}


Table 2. Primary Antibodies Used in the Study

\begin{tabular}{llccc}
\hline Antibody & Source & Type & Pretreatment & Dilution \\
\hline MLH1 & Dako $^{\circledR}$ & monoclonal mouse & pressure cooking 3 min & $1: 200$ \\
MSH2 & Dako $^{\circledast}$ & monoclonal mouse & pressure cooking 3 min & $1: 200$ \\
MSH6 & Dako $^{\circledR}$ & monoclonal rabbit & pressure cooking 3 min & Ready-to-use \\
PMS2 & Dako $^{\circledR}$ & monoclonal rabbit & pressure cooking 3 min & Ready-to-use \\
\hline
\end{tabular}
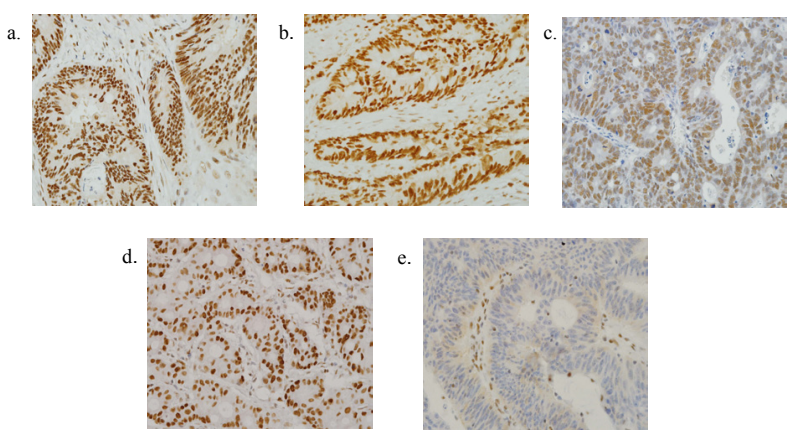

Figure 1. Immunohistochemical Staining (x200 magnification) for MMR Protein Expressions of a) Normal MLH1 b) Normal MSH2 c) Normal PMS2 d) Normal MSH6 e) Abnormal MLH1

a.

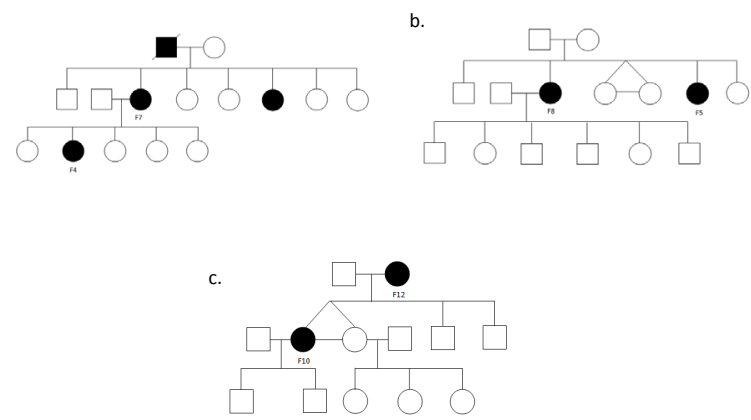

Figure 2. a) F4 is a First Degree Relative to F7, b) F5 is a First Degree Relative to F8, c) F10 have a First Degree Relationship with F12

Staining assessment and scoring

The immunohistochemical scoring analysis was performed by the pathologist based on the following semiquantitative scoring method. The presence of internal control immunopositivity (lymphocytes and benign colonocytes) was necessary for a valid result. The intensity (I) of immunoreactivity of the nuclear compartment of the malignant epithelial cells was measured on 0-3 scale. This scale was based on comparison of intensity of reactivity of the tumour cells with the positive control cells. A score of 0 indicated no reactivity, a score of 2 if moderate intensity and a score of 3 denoted an intensity of of tumour cell reactivity equivalent to positive control cells (Barrow et al., 2010).

The score of percentage (\%) of tumour cells staining were as follows; score 0 indicated no tumour cell immunopositivity, score 1 for $1-10 \%$ positive tumour cells, score 2 for $11-50 \%$ positive tumour cells, score 3 for $51-80 \%$ positive tumour cells and score 4 for $>80 \%$ positive tumour cells. The tumour cells were differentiated from tumour infiltrating lymphocytes which were also immunopositive (Muller et al., 2001).

The score of percentage and intensity were multiplied. The total scores of $\geq 4$ were considered positive and $<4$ as negative (Barrow et al., 2010).
Table 3. Immunohistochemical Staining Score of HNPCC-related CRC Patients.

\begin{tabular}{|c|c|c|c|c|}
\hline \multirow[t]{3}{*}{ Patient ID } & \multicolumn{4}{|c|}{ Immuhistochemical staining } \\
\hline & \multicolumn{4}{|c|}{$\begin{array}{c}\text { (percentage immunopositivity score } \\
\text { x staining intensity score) }\end{array}$} \\
\hline & MLH1 & MSH2 & MSH6 & PMS2 \\
\hline $\mathrm{F} 1$ & $\begin{array}{c}8 \\
(4 \times 2)\end{array}$ & $\begin{array}{c}12 \\
(4 \times 3)\end{array}$ & $\begin{array}{c}12 \\
(4 \times 3)\end{array}$ & $\begin{array}{c}12 \\
(4 \times 3)\end{array}$ \\
\hline F2 & $\begin{array}{c}8 \\
(4 \times 2)\end{array}$ & $\begin{array}{c}8 \\
(4 \times 2)\end{array}$ & $\begin{array}{c}12 \\
(4 \times 3)\end{array}$ & $\begin{array}{c}12 \\
(4 \times 3)\end{array}$ \\
\hline F3 & $\begin{array}{c}1 \\
(1 \times 1)\end{array}$ & $\begin{array}{c}12 \\
(4 \times 3)\end{array}$ & $\begin{array}{c}12 \\
(4 \times 3)\end{array}$ & $\begin{array}{c}1 \\
(1 \times 1)\end{array}$ \\
\hline F4 & $\begin{array}{c}2 \\
(2 \times 1)\end{array}$ & $\begin{array}{c}12 \\
(4 \times 3)\end{array}$ & $\begin{array}{c}12 \\
(4 \times 3)\end{array}$ & $\begin{array}{c}1 \\
(1 \times 1)\end{array}$ \\
\hline F5 & $\begin{array}{c}12 \\
(4 \times 3)\end{array}$ & $\begin{array}{c}12 \\
(4 \times 3)\end{array}$ & $\begin{array}{c}12 \\
(4 \times 3)\end{array}$ & $\begin{array}{c}6 \\
(3 \times 2)\end{array}$ \\
\hline F7 & $\begin{array}{c}1 \\
(1 \times 1)\end{array}$ & $\begin{array}{c}8 \\
(4 \times 2)\end{array}$ & $\begin{array}{c}12 \\
(4 \times 3)\end{array}$ & $\begin{array}{c}1 \\
(1 \times 1)\end{array}$ \\
\hline F8 & $\begin{array}{c}12 \\
(4 \times 3)\end{array}$ & $\begin{array}{c}12 \\
(4 \times 3)\end{array}$ & $\begin{array}{c}12 \\
(4 \times 3)\end{array}$ & $\begin{array}{c}12 \\
(4 \times 3)\end{array}$ \\
\hline F10 & $\begin{array}{c}12 \\
(4 \times 3)\end{array}$ & $\begin{array}{c}12 \\
(4 \times 3)\end{array}$ & $\begin{array}{c}12 \\
(4 \times 3)\end{array}$ & $\begin{array}{c}12 \\
(4 \times 3)\end{array}$ \\
\hline F11 & $\begin{array}{c}2 \\
(2 \times 1)\end{array}$ & $\begin{array}{c}12 \\
(4 \times 3)\end{array}$ & $\begin{array}{c}12 \\
(4 \times 3)\end{array}$ & $\begin{array}{c}0 \\
(0 \times 0)\end{array}$ \\
\hline F12 & $\begin{array}{c}8 \\
(4 \times 2)\end{array}$ & $\begin{array}{c}12 \\
(4 \times 3)\end{array}$ & $\begin{array}{c}12 \\
(4 \times 3)\end{array}$ & $\begin{array}{c}12 \\
(4 \times 3)\end{array}$ \\
\hline F13 & $\begin{array}{c}6 \\
(3 \times 2)\end{array}$ & $\begin{array}{c}3 \\
(3 \times 1)\end{array}$ & $\begin{array}{c}12 \\
(4 \times 3)\end{array}$ & $\begin{array}{c}12 \\
(4 \times 3)\end{array}$ \\
\hline F15 & $\begin{array}{c}12 \\
(4 \times 3)\end{array}$ & $\begin{array}{c}2 \\
(2 \times 1)\end{array}$ & $\begin{array}{c}2 \\
(2 \times 1)\end{array}$ & $\begin{array}{c}12 \\
(4 \times 3)\end{array}$ \\
\hline F16 & $\begin{array}{c}6 \\
(3 \times 2)\end{array}$ & $\begin{array}{c}4 \\
(2 \times 2)\end{array}$ & $\begin{array}{c}6 \\
(3 \times 2)\end{array}$ & $\begin{array}{c}4 \\
(2 \times 2)\end{array}$ \\
\hline F18 & $\begin{array}{c}12 \\
(4 \times 3)\end{array}$ & $\begin{array}{c}12 \\
(4 \times 3)\end{array}$ & $\begin{array}{c}12 \\
(4 \times 3)\end{array}$ & $\begin{array}{c}12 \\
(4 \times 3)\end{array}$ \\
\hline F19 & $\begin{array}{c}12 \\
(4 \times 3)\end{array}$ & $\begin{array}{c}12 \\
(4 \times 3)\end{array}$ & $\begin{array}{c}12 \\
(4 \times 3)\end{array}$ & $\begin{array}{c}12 \\
(4 \times 3)\end{array}$ \\
\hline F20 & $\begin{array}{c}12 \\
(4 \times 3)\end{array}$ & $\begin{array}{c}12 \\
(4 \times 3)\end{array}$ & $\begin{array}{c}6 \\
(2 \times 3)\end{array}$ & $\begin{array}{c}4 \\
(2 \times 2)\end{array}$ \\
\hline F21 & $\begin{array}{c}12 \\
(4 \times 3)\end{array}$ & $\begin{array}{c}8 \\
(4 \times 2)\end{array}$ & $\begin{array}{c}0 \\
(0 \times 0)\end{array}$ & $\begin{array}{c}0 \\
(0 \times 0)\end{array}$ \\
\hline
\end{tabular}

\section{Results}

Paraffin embedded tumour tissue samples were examined using 4 antibodies, MLH1, MSH2, MSH6 and PMS2. Table 3 showed the immunohistochemical scores for four antibodies tested on the tumour samples. Eleven out of 17 patients $(64.7 \%)$ were noted to have a family history. A total of $41 \%(n=7)$ of the patients had abnormal immunohistochemical staining in either four antibodies. As each patient was tested with four MMR antibodies, 13 tumour tissues demonstrated loss of expression with the negative stain of score $<4$. Of 13 tumour tissues, 4 out of 13 showed loss expression for MLH1, 5 out of 13 showed loss of expression for PMS 2 and 2 out of 13 showed loss of expression for MSH2 and MSH6 respectively (Table 3). 
Interestingly, six patients who had a family history satisfying the Bethesda criteria (Figure 2) also presented similar pattern of immunohistochemical staining with their corresponding relatives. The similar immunohistochemical staining pattern were acclaimed by the similar prominent immunohistochemical staining between each patient with their corresponding relative as both patients in the family (Figure 2a) demonstrated loss of immunohistochemical staining for MLH1 and PMS2. However, two patients in the two respective families (Figure $2 b$ and Figure 2c) showed normal protein expression in these tested four antibodies; MLH1, MSH2, MSH6 and PMS2.

\section{Discussion}

Revised Bethesda criteria was known to have a sensitivity and specificity of $91 \%$ and $77 \%$ respectively (Pinol et al., 2005). The incidence of HNPCC in the Malay population is still difficult to estimate. A reason to this factor might be due to lack of participation and awareness of those individuals with colorectal cancer risk to perform screening in Malaysia as compared to other countries (Yusoff et al., 2012). In contrast, a study revealed that increasing awareness on the importance of evaluating the family history among LS patient have increased the survival rate than sporadic colorectal cancer (Haghighi et al., 2009). In Malaysia and Singapore, where three major Asian races; Malay, Chinese and Indian live together, the incidence rate of CRC observed in Chinese have higher rates Indians and Malays (Goh et al., 2005). This is concordant with other study which stated that Malaysian Chinese have a clear predilection for CRC as compared to the Malaysian Indians and Malays (Cheah et al., 2014). CRC is often diagnosed in these patients at the mean age of 45 years old and is located in the proximal part of the colon in two thirds of cases. We have identified distinct features in family history of the individuals. The strong family association would probably be a strong risk factor in these individuals as there is an evidence that close relatives of individuals with CRC are at risk of developing extracolonic cancer (Coggins et al., 2005).

IHC staining is the appropriate way to detect the MMR dysfunction as by using IHC, the expression pattern of MLH1, MSH2, MSH6 and PMS2 was examined in primary tumours and in the corresponding normal mucosa from patients with CRC (Amira et al., 2014). Immunohistochemical analysis of colorectal tumours in HNPCC families has shown that the gene product from the mutated MMR gene is absent in tumour tissue and at the same time present in adjacent normal tissue (Thibodeau et al., 1996).

In this study, we found a noticeable loss of expression in four and five cases for MLH1 and PMS2 respectively as the abnormality of MLH1 is accompanied by abnormality of PMS2 due to heterodimeric association of proteins (Arends et al., 2008). Abnormal MMR protein expression can be detected in two patterns: either complete loss of expression (when there is no expression of that MMR protein or only expression of a truncated protein to which the antibody does not bind or the mutated protein has lost the epitope recognized by the antibody), or patchy/ weak expression (if the mutation generates a prematurely truncated but variably stable protein, or a protein with alterations to the epitope recognized by the antibody, such as may be the case with some missense mutations) (Poulogiannis et al., 2009). A deleterious mutation resulting in an absent or truncated protein will usually result in a complete loss of reactivity. However, certain pathogenic mutations (including frame shift mutations) may leave protein product that retains antigenicity, resulting in false-positive immunoreactivity (normal protein staining persists). This is dependant on the location of the antibody binding site on the protein, the site of mutation, and the effect of the mutation on normal gene expression and protein maturation (Barrow et al., 2010). Mutations may also have destroyed the enzymatic activity while preserving the immunoreactivity and stability of proteins (Southey et al., 2005). MMR plays a vital role in the control of processes occurring during oncogenesis in the majority of HNPCC cases (Marra et al., 2005). However, in a small proportion of 5 to $20 \%$ of HNPCCrelated tumours do not demonstrate any abnormality or loss of protein expression on analysis by IHC even though they have lost MMR function. This may due to the mutations that functionally inactivate the MMR protein but allow its expression as a stable protein with nuclear localisation and intact epitope (Arends et al., 2008).

However, in this study, although we noted six cases of $\mathrm{CRC}$ with strong family history, the immunohistochemical analysis done only showed two cases with absence of immunohistochemical staining among these families. The familial risk may not be entirely due to LS but the MMR abnormalities may be associated to the role of susceptibility. The abnormalities of the MLH1 deficient CRC may be not expressed due to early diagnosis as the MLH1 deficient tend to occur at a later age of 75 years old for a family history of colorectal cancer or HNPCC spectrum and also in the absence of family history (Coggins et al., 2005).

In conclusion, revised Bethesda criteria and immunohistochemical analysis constituted a convenient approach and is recommended to be a first-line screening for Lynch syndrome in Malay cohorts. It is also able to add significant information to support the increased risk of developing colorectal or other cancers in most families with HNPCC.

\section{Acknowledgement}

We would like to acknowledge Universiti Sains Malaysia for providing us a research university grant (1001/PPSP/812112) and USM APEX Delivering Excellence 2012 (1002/PPSP/910343), to complete the study.

\section{References}

Amira AT, Mouna T, Ahlem B, et al (2014). Immunohistochemical expression pattern of MMR protein can specifically identify patients with colorectal cancer microsatellite instability. Tumor Biol, 35, 6283-91.

Arends M, Ibrahim M, Happerfield L, et al (2008). Interpretation 

of immunohistochemical analysis of mismatch repair (mmr) protein expression in tissue sections for investigation of suspected Lynch/hereditary non-polyposis colorectal cancer (HNPCC) syndrome. UK NEQAS ICC \& ISH Recommendations, 1.

Barrow E, Jagger E, Brierley J, et al (2010). Semiquantitative assessment of immunohistochemistry for mismatch repair proteins in Lynch syndrome. Histopathology, 56, 331-44.

Cheah PL, Looi LM, Teoh KH, et al (2014). Colorectal carcinoma in Malaysians: DNA mismatch repair pattern in a multiethnic population. Asian Pac J Cancer Prev, 15, 3287-91.

Coggins RP, Cawkwell L, Bell SM, et al (2005). Association between family history and mismatch repair in colorectal cancer. Gut, 54, 636-42.

Goh KLl, Quek KFf, Yeo GTSts, et al (2005). Colorectal cancer in Asians: a demographic and anatomic survey in Malaysian patients undergoing colonoscopy. Aliment Pharm Therap, 22, 859-864.

Haghighi MM, Vahedi M, Mohebbi SR, et al (2009). Comparison of survival between patients with hereditary non polyposis colorectal cancer (HNPCC) and sporadic colorectal cancer. Asian Pac J Cancer Prev, 10, 497-500.

Lynch HT, de la Chapelle A (2003). Hereditary colorectal cancer. $N$ Engl J Med, 348, 919-32.

Murad NAA, Othman Z, Khalid M, et al (2012). Missense mutations in MLH1, MSH2, KRAS, and APC genes in colorectal cancer patients in Malaysia. Digest Dis Sci, 57, 2863-72.

Piñol V, Castells A, Andreu M, et al (2005). Accuracy of revised Bethesda guidelines, microsatellite instability, and immunohistochemistry for the identification of patients with hereditary nonpolyposis colorectal cancer. JAMA, 293,16, 1986-1994.

Southey MC, Jenkins MA, Mead L, et al (2005). Use of molecular tumor characteristics to prioritize mismatch repair gene testing in early-onset colorectal cancer. J Clin Oncol, 23, 6524-6532.

Thibodeau SN, French AJ, Roche PC, et al (1996). Altered expression of hMSH2 and hMLH1 in tumors with microsatellite instability and genetic alterations in mismatch repair genes. Cancer Res, 56, 4836-40.

Toft NJ, Arends MJ (1998). DNA mismatch repair and colorectal cancer. J Pathol, 185, 123-9.

Vasen HF, Möslein G, Alonso A, et al (2007). Guidelines for the clinical management of Lynch syndrome (hereditary non-polyposis cancer). J Med Genet, 44, 353-62.

Yusoff HM, Daud N, Noor NM, et al (2012). Participation and barriers to colorectal cancer screening in Malaysia. Asian Pac J Cancer Prev, 13, 3983-7.

Zahary MN, Kaur G, Hassan MRA, Singh H, Naik VR, Ankathil R (2012). Germline mutation analysis of MLH1 and MSH2 in Malaysian Lynch syndrome patients. World $J$ Gastroenterol, 18, 814. 